\title{
Impact of Some Natural Derivatives on the Oxidative Stability of Soybean Oil Based Biodiesel
}

\author{
Min Luo, Ren-Yu Zhang, Zhi Zheng, Jian-li Wang* and Jian-Bing Ji \\ College of Chemical Engineering and Materials Science, \\ Zhejiang University of Technology, Hangzhou 310014, P. R. China
}

\begin{abstract}
Cinco derivados naturais [ácido ferúlico (FA), polifenol de chá lipidio-solúvel (LTP), polifenol de chá solúvel em água (WTP), sesamol (SE) e ácido cafeico (CA)] foram avaliados como aditivos antioxidantes para melhorar a estabilidade da oxidação de biodiesel de óleo de soja (SBO-BD). Verificou-se que WTP, LTP, SE e CA podem melhorar significativamente a estabilidade de SBO-BD. CA apresentou o melhor desempenho no intervalo de concentração de 500 a 1500 ppm, enquanto que WTP mostrou atividade mais elevada a uma concentração de 200 ppm. Para comparação, o efeito estabilizador de três antioxidantes sintéticos $[\alpha$-tocoferol $(\alpha-\mathrm{T})$, butilhidroxitolueno (BHT) e butilhidroxianisol (BHA)] foi avaliado simultaneamente. Os resultados mostraram que o efeito de alguns aditivos naturais (WTP, LTP, SE e CA) foi melhor que de aditivos sintéticos ( $\alpha$-T, BHT e BHA) na estabilidade da oxidação de SOB-BD. Uma explicação possível para os efeitos diferentes entre os antioxidantes testados foi elaborada levando em conta sua estrutura molecular.
\end{abstract}

Five natural derivatives [ferulic acid (FA), lipid-soluble tea polyphenol (LTP), water-soluble tea polyphenol (WTP), sesamol (SE) and caffeic acid (CA)] were evaluated as antioxidative additives for enhancing the oxidation stability of soybean oil based biodiesel (SBO-BD). It was found that WTP, LTP, SE and CA could significantly improve the oxidation stability of SBO-BD. CA displayed the best performance in the concentration range from 500 to $1500 \mathrm{ppm}$, whereas WTP displayed the highest activeness at a concentration of $2000 \mathrm{ppm}$. For comparison, the stabilizing effect of three synthetic anti-oxidants $[\alpha$-tocopherol $(\alpha-\mathrm{T})$, butylhydroxytoluene (BHT) and butylhydroxyanisol (BHA)] was simultaneously evaluated. The results showed that the effect of some natural additives (WTP, LTP, SE and CA) was better than that of synthetic additives ( $\alpha-\mathrm{T}$, BHT and BHA) on the oxidation stability of SBO-BD. A possible explanation for the different effects among the tested antioxidants was given based on their molecular structures.

Keywords: biodiesel, oxidation stability, antioxidant, natural derivatives, Rancimat method

\section{Introduction}

The increasing cost and the depletion of petroleumbased fuels have stimulated the recent interest in alternative sources. Fat acid methanol esters (FAME), known as biodiesel, are a possible alternative fuel prepared from renewable resources, such as vegetable oils, animal fats or cooking oil, by transesterification with methanol. ${ }^{1}$ The production capacity of biodiesel has considerably grown in the past several years. According to the statistics of the European Biodiesel Board (EBB), the biodiesel production in the European Union expanded from 7.755 million tonnes in 2008 to 9.045 million tonnes in $2009 .^{2}$ This may further

*e-mail: wangjl@zjut.edu.cn increase since Europe targeted a 10\% addition of biodiesel at the car fuels by the year $2020 .^{3}$

There are many advantages in using biodiesel in vehicles. ${ }^{4}$ However, the storage stability of biodiesel is not desirable owing to its poor anti-oxidation property. The high-level unsaturated (carbon-carbon double bond) longchain alkyl in FAME molecules makes biodiesel prone to be oxidized or oligomerized as compared to petroleum diesel. The cleavage or the combination of carbon-carbon double bonds produces numerous components such as carboxylic acids, alcohols, peroxides, as well as oligomers. Carboxylic acids may increase the acidity of biodiesel, leading to the corrosion of the engine in the vehicles. The formation of the oligomers increases the viscosity of fuel and the insoluble oligomers plug the injection system..$^{5-7}$ Normally, 
the oxidation stability of biodiesel is estimated through the detection of its induction period (IP) using Rancimat test method. ASTM (American Society for Testing and Materials) D6751-07 norm has set an oxidation stability standard of a three-hour minimum IP. ${ }^{8}$ The European Committee for Standardization (CEN) adopted a minimum IP of six-hour as the specification. In 2007, China published GB/T 20828-2007 national standard, in which six-hour minimum IP was required as the usual. ${ }^{9}$

To improve the oxidation stability of biodiesel, one strategy is to decrease its degree of unsaturation by hydrogenation, ${ }^{10,11}$ which, however, may increase the freezing point of the fuel. Another option is simply to add antioxidants to biodiesel. It is well known that antioxidants can prevent the oxidation of food, oil, chemicals, plastics etc. Numerous works had been performed to study the influence of antioxidants on the oxidation stability of biodiesel. ${ }^{12-19}$ Domingos et al. ${ }^{12}$ reported the effect of synthetic antioxidants, such as butylhydroxytoluene (BHT), butylhydroxyanisol (BHA) and $t$-butylhydroxyquinone (TBHQ), on the oxidation stability of soybean oil ethyl esters. The results revealed BHT with the best performance on improving the IP of biodiesel in the concentration range of 200-7000 ppm, whereas TBHQ displayed a greater effectiveness when used at 8000 ppm. ${ }^{12}$ De Guzman et al. ${ }^{13}$ evaluated the cooperative effects of different antioxidants on the oxidative stability of soybean oil and poultry fat based biodiesels. It was found that the cooperated antioxidants performed better than single one. ${ }^{13}$ Tang et al. ${ }^{14}$ found that pyrogallol (PY), propylgallate (PG) and TBHQ can significantly improve the IP of soybean oil, cotton seed oil, poultry fat and yellow grease based biodiesels, while PY, BHA and BHT showed the best results for poultry fat based biodiesel. Mittelbach and Schober ${ }^{15}$ reported that the stability of biodiesels derived from apeseed oil, used frying oil, and tallow was considerably improved with PY, PG, and TBHQ additions, whereas antioxidant BHT was not very effective.

Natural antioxidant extracted from plant is renewable, safe and is widely used in food industry. So far, few works about the natural additives stabilizing biodiesel were reported. In this work, five natural antioxidants [watersoluble tea polyphenol (WTP), lipid-soluble tea polyphenol (LTP), ferulic acid (FA), sesamol (SE) and caffeic acid (CA)] were added into soybean oil based biodiesel (SBO-BD) to estimate how effective these additives are to protect SBO-BD from oxidation. This was accomplished through induction period method of the samples. Three synthetic antioxidants [ $\alpha$-tocopherol $(\alpha-\mathrm{T})$, butyl-hydroxytoluene (BHT) and butylhydroxyanisol (BHA)] were selected for comparative investigation.

\section{Experimental}

\section{Additives}

Ferulic acid $(\mathrm{FA},>99 \%)$, sesamol (SE, > 98\%), caffeic acid (CA, > 98\%), $\alpha$-tocopherol $(\alpha-\mathrm{T},>96 \%)$, butylhydroxytoluene (BHT, $>99 \%$ ) and butylhydroxyanisol (BHA, > 98\%) were purchased from Aladdin (Shanghai, China). Water-soluble tea polyphenol (WTP, containing $33 \%$ of epigallocatechin gallate, $45 \%$ of epicatechin, $20 \%$ of epigallocatechin and $2 \%$ of water) was purchased from Wuhu Tianyuan Science and Technology Development Co., Ltd. (Anhui, China), lipid-soluble tea polyphenol (LTP, containing $70 \%$ of oleic acid, $15 \%$ of epigallocatechin gallate oleate, $7 \%$ of epicatechin oleate, $5 \%$ of epigallocatechin oleate and $3 \%$ of water) was purchased from Pulimeidi Biotech (Hangzhou) Co., Ltd. (Zhejiang, China).

\section{Preparation of SBO-BD and samples}

SBO-BD was prepared by employing the ultrasonic method. ${ }^{20}$ A certain amount of soybean oil was poured into a jacket-reactor equipped with a transducer controlled by the ultrasonic generator and a condensator, and heated by water bath up to $45^{\circ} \mathrm{C}$. The reaction began when the methanol liquor dissolved in $\mathrm{NaOH}$ was poured into the preheated reactor. The reaction conditions are described as follows: the molar ratio of methanol to soybean oil was $6: 1$, the ultrasonic power was $150 \mathrm{~W}$, the pulse frequency was 1.0 , and the reaction temperature was $45^{\circ} \mathrm{C}$. After 30 min reaction, the mixture was purified according to the procedure reported in the literature. ${ }^{20}$ Properties of prepared SBO-BD are shown in Table 1.

Table 1. Properties of SBO-BD prepared by using ultrasonic method

\begin{tabular}{lc}
\hline Properties & SBO-BD \\
\hline Total ester content / wt.\% & 99.8 \\
Flash point / ${ }^{\circ} \mathrm{C}$ & 170 \\
Density $\left(20^{\circ} \mathrm{C}\right) /\left(\mathrm{kg} \mathrm{m}^{-3}\right)$ & 879.5 \\
Kinematic viscosity $\left(40{ }^{\circ} \mathrm{C}\right) /\left(\mathrm{mm}^{2} \mathrm{~s}^{-1}\right)$ & 4.06 \\
Acid value / $\left(\mathrm{mg} \mathrm{KOH} \mathrm{g}{ }^{-1}\right)$ & 0.56 \\
Free glycerol / wt.\% & 0.015 \\
Total glycerol / wt.\% & 0.17 \\
Water content / wt. $\%$ & 0.001 \\
Induction period / h & 2.6 \\
Alkaline metals: $\mathrm{K}+\mathrm{Na} /\left(\mathrm{mg} \mathrm{kg}^{-1}\right)$ & 5.6 \\
\hline
\end{tabular}

\section{Sample preparation and IP testing}

Each of the natural and the synthetic antioxidants, with concentrations ranging from 500 to 2000 ppm, was 
added into SBO-BD and dissolved thoroughly by means of vigorous mechanical agitation. The IP of each sample was tested according to Rancimat test method (EN 14112) using a ST14112-2 Rancimat instrument (Wuhan Songtao Analytical Instrument Co., Ltd., Hubei, China). Samples of $3 \mathrm{~g}$ were analyzed under a constant air flow rate of $10 \mathrm{~L} \mathrm{~h}^{-1}$ and a heating block temperature of $110{ }^{\circ} \mathrm{C}$. The temperature correction factor was set to $1.5^{\circ} \mathrm{C}$ as recommended by the manufacturer.

\section{Results and Discussion}

\section{The effects of the natural additives}

The effects of the natural antioxidants (FA, LTP, WTP, SE and CA) on the oxidation stability of the samples are shown in Figure 1. In general, all of the tested additives had a positive influence on the oxidation stability of SBO-BD. Among these natural antioxidants that were evaluated, a significant difference in activity was observed. The effectiveness of FA was found to be relatively poor when compared to the other natural additives. FA did not improve the IP of SBO-BD enough to reach the minimum specification limit of $6 \mathrm{~h}$, even at the concentration of $2000 \mathrm{ppm}$. Whereas LTP at $2000 \mathrm{ppm}$, WTP or SE at $1000 \mathrm{ppm}$, and CA at $500 \mathrm{ppm}$ achieved the IP over $6 \mathrm{~h}$. The relative ineffectiveness of FA was surprising, because this substance is commonly used as antioxidant for many types of food products. As the concentrations ranged from 500 to $1500 \mathrm{ppm}$, CA was found to be the most efficient antioxidant in terms of increasing the IP of SBO-BD, SE was the second most effective antioxidant, followed by WTP and LTP. When the concentration was up to $2000 \mathrm{ppm}$, WTP behaved as the most effective antioxidant.

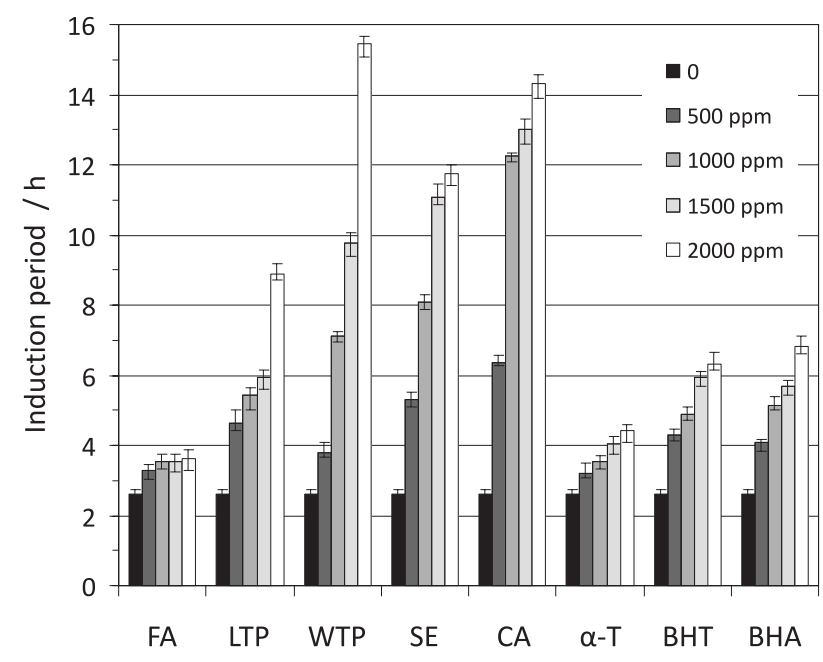

Figure 1. Influence of antioxidant concentration on the oxidation stability of SBO-BD.
The effects of the synthetic additives

The influence of synthetic antioxidant $(\alpha-\mathrm{T}$, BHT or BHA) on the oxidation stability of SBO-BD is illustrated in Figure 1. In general, the addition of $\alpha-T$, BHT and BHA was found to increase the IP. The effects of BHT and BHA were very close to each other, while $\alpha$-T exhibited a relatively poor activity. The IPs of all samples containing $\alpha$-T were less than $6 \mathrm{~h}$, while BHT or BHA at 2000 ppm could help SBO-BD to achieve an IP over $6 \mathrm{~h}$. The weak effectiveness of $\alpha$-T for stabilizing SBO-BD was also mentioned by Dunn ${ }^{21}$ and Tang et al..$^{14}$ However, Tang et al. ${ }^{14}$ reported that BHT and BHA increased the IP of SBO-BD over $6 \mathrm{~h}$ at $1000 \mathrm{ppm}$. Different results on the antioxidant effects may be due to differences in the biodiesel feedstocks and experimental protocols.

It is observed from Figure 1 that some natural additives (WTP, SE and CA) displayed much more effectiveness than synthetic antioxidants ( $\alpha-\mathrm{T}$, BHT and BHA). LTP also behaved much better than $\alpha-\mathrm{T}$, BHT and BHA at a concentration of $2000 \mathrm{ppm}$, but FA exhibited as the least active antioxidant. In the next section, a possible explanation is given to elucidate the differences in activity among the antioxidants used in this work with foundation on their molecular structures.

\section{Mechanism discussion}

The effectiveness of the antioxidants used in this research can be explained on the basis of their chemical structures. Generally, the active phenolic hydroxyl group can provide protons to inhibit the formation of free radicals, so as to delay the rate of oxidation..$^{13,19}$ It is noted from Scheme 1 that the difference between the molecular structure of FA and CA is just that CA has two phenolic hydroxyl groups attached to the aromatic ring, while FA has one phenolic hydroxyl group and one methoxyl group at the same position attached to the benzene ring. Therefore, on the basis of electronegativity, it can be concluded that CA is more active than FA. Similar explanation had been mentioned by Karavalakis and Stournas, ${ }^{18}$ who claimed that TBHQ, PG and PA possess two phenolic hydroxyl groups, but BHT, as well as BHA, possesses one phenolic hydroxyl group. Thus, TBHQ, PG and PA performed much better than BHT and BHA antioxidants in the improvement of the oxidation stability of SBO-BD.

SE contains one phenolic hydroxyl group, moreover, there is another ring containing two oxygen atoms that are attached to the aromatic ring. So, the conjugated effect between the two oxygen atoms with lone pair electrons and the benzene ring may increase the electronegativity of the 
<smiles>O=C(O)/C=C/c1ccc(O)c(O)c1</smiles>

Caffeic acid<smiles>COc1cc(/C=C/C(=O)O)ccc1O</smiles>

Ferulic acid

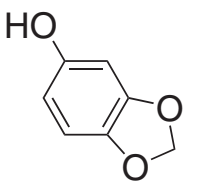

Sesamol<smiles>Cc1cc(C(C)(C)C)c(O)c(C(C)(C)C)c1</smiles>

BHT<smiles>COc1ccc(O)c(C(C)(C)C)c1</smiles>

BHA<smiles>Cc1c(C)c2c(c(C)c1O)CCC(C)(CCCC(C)CCCC(C)CCCC(C)C)O2</smiles>

Alpha-T

Scheme 1. Molecular structures of cafferic acid, ferulic acid, sesamol, BHT, BHA and $\alpha-$ T.

benzene ring and decrease the electronegativity, as well as the polarity of the two oxygen atoms, resulting in the easy oxidation of SE. SE has three phenolic hydroxyl groups, being that two of them are methylated. Similarly, FA contains two phenolic hydroxyl groups, but one of them is etherified. Therefore, SE should be more effective than FA. CA has one more phenolic group without substitution than SE, so that, CA should be more active than SE. Hence, SE behaved better than FA but worse than CA on improving the IP of SBO-BD.

Each of BHT, BHA and $\alpha-T$ has only one phenolic hydroxyl group and lack of strong electron-donating group, the resultant activity of BHT, BHA and $\alpha$-T antioxidants should be relatively low as compared to $\mathrm{CA}$ and SE natural additives. Furthermore, BHT contains two tertiary butyl groups and one methyl group, all of these groups can enhance the electronegativity of the benzene ring due to the hyper conjugation effect. Similarly, BHA has one tertiary butyl group and one methoxyl group to activate the benzene ring. Therefore, BHT and BHA behaved better than FA. $\alpha-\mathrm{T}$ contains a long carbon chain which may increase the steric hindrance when the oxidation occurs. This may explain the fact that $\alpha$-T displayed a less effectiveness than BHT and BHA antioxidants, but displayed similar effectiveness to FA. Therefore, it can be concluded that, the effect of the antioxidant does not only depend on the number of its phenolic hydroxyl groups, but is also related to other groups contained in the antioxidant molecule.

Scheme 2 shows the chemical structures of the polyphenols which are epicatechin, epigallocatechin and epigallocatechin gallate involved in WTP used in this research. Apparently, the polyphenols possess more phenolic hydroxyl groups which dominate the performance of the antioxidants than any additive shown in Scheme 1. Thus, the behavior of WTP natural additive on protecting SBO-BD against oxidation should be relatively much better. LTP used in this research contains epigallocatechin gallate oleate, epicatechin oleate and epigallocatechin oleate (Scheme 3). The esterification brings a long carbon chain which is similar to the fatty acid methyl ester in SBO-BD to epicatechin, epigallocatechin, and epigallocatechin gallate. This causes the steric hindrance as LTP is oxidized, resulting in LTP with less effectiveness than WTP. Moreover, the esterification of epicatechin,<smiles>Oc1cc(O)c2c(c1)OC(c1ccc(O)c(O)c1)C(O)C2</smiles>

Epicatechin<smiles>Oc1cc(O)c2c(c1)OC(c1cc(O)c(O)c(O)c1)C(O)C2</smiles>

Epigallocatechin<smiles>O=C(OC1Cc2c(O)cc(O)cc2OC1c1cc(O)c(O)c(O)c1)c1cc(O)c(O)c(O)c1</smiles>

Epigallocatechin gallate

Scheme 2. Chemical structures of the compositions in WTP: epicatechin, epigallocatechin and epigallocatechin gallate. 
<smiles>O=C(O)c1cc(C2Oc3cc(O)cc(O)c3CC2O)ccc1O</smiles>

Epicatechin oleate<smiles>O=C(O)Oc1cc(C2Oc3cc(O)cc(O)c3CC2O)cc(O)c1O</smiles>

Epigallocatechin oleate<smiles>[R][C]1c2c(O)cc(O)cc2OC(c2cc(O)c(O)c(OC=O)c2)C1OC(=O)c1cc(O)c(O)c(O)c1</smiles>

Epigallocatechin gallate oleate

\section{$\mathrm{R}=\mathrm{H}_{3} \mathrm{C}\left(\mathrm{H}_{2} \mathrm{C}\right)_{7} \mathrm{HC}=\mathrm{CH}\left(\mathrm{CH}_{2}\right)_{6} \mathrm{CH}_{2}^{-}$}

Scheme 3. Chemical structures of the compositions in LTP: epicatechin oleate, epigallocatechin oleate and epigallocatechin gallate oleate.

epigallocatechin and epigallocatechin gallate also reduces the number of their phenolic hydroxyl groups, leading to the relatively low activity of LTP as compared to WTP.

\section{Conclusions}

In this study, the effect of five natural antioxidants (FA, LTP, WTP, SE and CA) was experimentally evaluated on the oxidation stability of SBO-BD. In general, the addition of all the natural antioxidants can improve the oxidation stability of SBO-BD. Among these five natural antioxidants, WTP, SE and CA produced a significant improvement on the IP of SBO-BD, whereas FA displayed no noticeable improvement. The order of the stabilizing effect of all the natural additives within the concentration range from 500 to $1500 \mathrm{ppm}$ on SBO-BD is described as follows: CA $>$ SE $>$ WTP $>$ LTP $>$ FA. When the concentration of the additive was up to $2000 \mathrm{ppm}$, WTP displayed as the best antioxidant. The effect of three synthetic antioxidants $(\alpha-\mathrm{T}$, BHT and BHA) was investigated for comparison. The results indicated that these synthetic antioxidants were less effective than some natural additives (WTP, LTP, $\mathrm{SE}$ and $\mathrm{CA}$ ). A possible explanation for the differences in activity among the tested antioxidants was given based on their molecular structures. It can be concluded that, the effect of the antioxidant is related not only to its phenolic hydroxyl groups, but also to other groups contained in the antioxidant molecule.

\section{Acknowledgement}

The authors would like to thank for financial support from Science and Technology Program (No. 2008C21025)
\& Natural Science Foundation (Y4080530) of Zhejiang Province, China.

\section{References}

1. Meher, L. C.; Sagar, D. V.; Naik, S. N.; Renew. Sust. Energ. Rev. 2006, 10, 248.

2. http://www.ebb-eu.org/stats.php accessed in July 2011.

3. The European Association for Bioindustries (EuropaBio); Biofuels in Europe, EuropaBio Position and Specific Recommendations; EuropaBio: Europe, 2007, available at http://www.europabio.org/sites/default/files/position/biofuels_ in_europe.pdf accessed in August, 2007.

4. Chang, D. Y. Z.; Gerpen, J. H. V.; Lee, I.; Johnson, L. A.; Hammond, E. G.; Marley, S. J.; J. Am. Oil Chem. Soc. 1996, 73,1549 .

5. Waynick, J. A.; Characterization of Biodiesel Oxidation and Oxidation Products (CRC Project No. AVFL-2b); The coordinating Research Council (CRC): Alpharetta, GA, 2005, available at http://www.nrel.gov/vehiclesandfuels/npbf/pdfs/39096.pdf accessed in August, 2005.

6. Paligova, J.; Joríková, L.; Cvengros, J.; Energy Fuels 2008, 22 , 1991.

7. Monyem, A.; Van Gerpen, J. H.; Biomass Bioenergy 2001, 20, 317.

8. ASTMD6751-07: Standard Specificationfor Biodiesel Fuel Blend Stock (B100) for Middle Distillate Fuels, Philadelphia, 2007.

9. GB/T 20828-2007: Biodiesel Blend Stock (BD100) for Disel Engine Fuels, China, 2007.

10. Pérez-Cadenas, A. F.; Zieverink, M. M. P.; Kapteijn, F.; Moulijn, J. A.; Carbon 2006, 77, 173.

11. Yang, R.; Su, M. X.; Li, M.; Zhang, J. C.; Hao, X. M.; Zhang, H.; Bioresour. Technol. 2010, 101, 5903. 
12. Domingos, A. K.; Saad, E. B.; Vechiatto, W. W. D.; Wilhelm, H. M.; Ramos, L. P.; J. Braz. Chem. Soc. 2007, 18, 416.

13. de Guzman, R.; Tang, H. Y.; Salley, S.; Simon Ng, K. Y.; J. Am. Oil Chem. Soc. 2009, 86, 457.

14. Tang, H. Y.; Wang, A. F.; Salley, S. O.; J. Am. Oil Chem. Soc. 2008, 85, 373.

15. Mittelbach, M.; Schober, S.; J. Am. Oil Chem. Soc. 2003, 80, 817.

16. Schober, S.; Mittelbach, M.; Eur. J. Lipid Sci. Technol. 2004, 106, 382.
17. Tang, H. Y.; de Guzman, R.; Salley, S.; Simon Ng, K. Y.; Lipid Technol. 2008, 20, 249.

18. Karavalakis, G.; Stournas, S.; Energy Fuels 2010, 24, 3682.

19. Liang, Y. C.; May, C. Y.; Foon, C. S.; Ngan, M. A.; Hock, C. C.; Basiron, Y.; Fuel 2006, 85, 867.

20. Ji, J. B.; Wang, J. L.; Li, Y. C.; Yu, Y. L.; Xu, Z. C.; Ultrasonics 2006, 44, e411.

21. Dunn, R. O.; Fuel Process. Technol. 2005, 86, 1071.

Submitted: March 26, 2011

Published online: November 22, 2011 